\title{
REVISTA - DE REVISTA
}

\section{LA URGENCLA QUIRURGICA EN EL EMBARAZO ECTOPICO}

Gin y Obs, de México, Vol. VI-1951: Ni 6.

\section{Por LUIS CESTELRZO AYALA}

Aprovechando el materal del I. M. S. S., en el que halló un porcentaje de 0.23 sobre 18.279 partos, el autor ancliza las síntomas clársicos del E. ectópico y los compara con los por él hallados.

Como resumen $y$ conclusiones anota:

19-El cuadro de embarazo ectópico ciásicamente descrito en sus diferen. tes períodos evolutivos se presenta en una minoria de casos. El diagnóstico ofrece con frecuencia dificultades serias que en ocasiones son insupera. bles.

$2^{a}-\mathrm{La}$ gran mayoría de casos $(94.7 \%$ ) en los que se presenta hemo. peritoneo la hemorragia se suspende mucho antes de que la cantidad de sangre sea suficiente para producir el sindrome de hemorragia interna con colapso o sincope. Casi todos $(90.5 \%)$ los casos de choque presentaron he. moperitoneo moderado y ausencia de scngrado en el momento de ser opera dos.

$3^{a-E l}$ cuadro agudo doloroso que puede o no Vlegar al choque se pro duce por la supture viscoral. $4^{\text {a }}$ - En todos los casos de- choque debe intentarse $\mathrm{la}^{-}$-identificación del factor que lo está produciendo; si es éste la-inundación peritoneal o hay duda que lo sea, la aplicación inme diata de sangre, plasma y sueros y la Japarotomía de urgencia se imponen. Conviene aprovechar para operar la mejoría transitoria que la fleboclisis produce.

$5^{\circ}-\mathrm{Si}$ puede comprobarse que en el cuadro agudo doloroso o en el colapso si llega a producirse, no interviene la cantidad de sangre por ser pequeña, debe esperarse utilizando una estrecha vigilancia armada a que las condiciones generales mejoren con los recursos médicos lo suficiente para que sean compatibles con un mínimo riesgo quirúrgico.

$6^{9}-$ En los casos en que el síndrome agudo no ya acompañado de choque, la urgencia quirúrgica depende de que el proceso presente o no carac teres de acentuación progresiva. En el primer caso interventr con pre mura proporcional a la rapidez con la que arance el cuadiro putolígice $y$ en el segundo esperar a mojorar los condiciones de la paciente, En ambos casos se debe aplicar de inmediato una transfusión sanguinea tan copiosa como so juzque necesario.

$7^{\circ}$ - Los resultados obtonidos con el maneje relativamente conservadar son excelentes y hacen esperar que la 
aplicación de todas las medidas que proponemos arroje un saldo cuín más satisfactorio. Por lo menos, el riesgo quirúrgico de la enferma se reducirá con ello considerablemente.

\section{BIBLIOGRAFIA}

1-Zenteno G. G. Consideraciones fisiopatológicas sobre el síndrome agudo de ruptura de embarazo tubario. Cirugía y Cirujanos, 9, 6: 235-255, junio 1941.

\section{Algunos puntos de técrica da operacao cesarecma.}

Octavio Rodríguez Lima. Obst. y Gin. Latinoam. Vol. X. Enero y febrero de 1952.

Hace un estudio de la armonía que debe haber entre las cualidades de partero y ciruiano y afirma que no debe marcharse a la intervención quirúrgica con la emesma intrepidez audaciosa dos primitivos conquistadores", pues si bien es cierto que $a$ veces surge imperiosa $\Theta$ inopinadamente la indicación de ia cesárea, en otras el buen criterio del obstetra no debe desdeñar la posibilidad de la vía alta y pór lo tánto es su obligación colocar or su paciente en las mejores condicio nes.

En su Servicio de-la Facultad de Medicina de la Untversidad del Brasil el autor ha establecido las siguientes normas:

19.-Administraçâo de penicilina $(400.000 \mathrm{u})$ após 12 horas de trabalho de parto, repetidas de $12 \mathrm{em} 12$ ho tas.

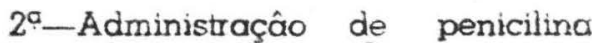
após 6 horas de rotura de bolsa daguas, independente da duracao do trabalho.

$3^{a}$-Transfusao de 500 c. c. de sangre total en parturiente com $60 \%$ de hemoglobina, ou abaixo desse teor.

4 - -Soro hipertóniço e vitamina C endovenosos no inicio do trabalho, repetindo de 6 em 6 horas.

5 a-Vifamina Bl (100 mgr.), intramuscular, en todas las parturientes.

$6^{a}$-Oxigenio sob pressao, ao menor sinal de sofrimento fetal oa de estafa materna:

Desta forma, caso sourevenha una indicaçâo para o parto cesareo, já está a parturiente protegida contra $\alpha$ infecçáo melhor amparada con tra - choque, causas tao freguentes, outrora, dos insucesos operatorios.

Resolvida a-intervencao surge o problema anestesia. Convirá tazer uma anestesia de base? Somos decldidamente contrarios aos barbitúricos endovenosos ha operacao cesareana. Em pacientes excessivamente pusilamines, admitimos, como exceçâo, o Demerol, sempre com cuidado de ad. ministrar logo oxigenio sob pressao. Reservamos a anestesia caudal para as pacientes hipertensas, $\theta$ de rotine empregnamos o cielopropano, pois este gaz permite misturas mais ricas em oxdgenio.

Para a obtençâo de un bom relaxa mento muscular, com a dose minime do ciclo, empregnamos o curare. Tist Ferraz, do nosso servico de anestestologia, assim sintetisa em um sea trabalho: *o curare representa uma dem mals eficlentes cocutílcoes da comes: 
tesiologría, permitindo conciliar aquels dois pontos diametralmente opostos, conseguindo assimo un relaxamento muscular adequado, con niveis de anestesia muito leves.

O curare em doses reduzidas e com os cuidados da tecnica é inocuo ao feto, conforme numerosas observo çôes de nosso serviçô e permite uma notavel teduçấo de ciclopropano na primi eira fase da operaçâos.

\section{Taraiba coded del úlero grávido.}

F. Orengo Díaz del Castillo. Rev. Española de Obste. y Gin. No 62. Valencia. Abril de 1952.

Se transcribe el resumen hecho por el mismo autor de un ensayo monográfico sobre tan raro accidente obsfétrico:

Se describe un caso mortal de tor sión axial aguda del útero normal en la. semana 38 del embarazo. La pel vis era estrecha y asimétrica y el feto estaba en situación transversal. El útero se torsionó vez y media hacia la izquierda (unos 270 grados).

La torsión coxial del útero grávido con thbromiomas o malformado (bicorne), es relativamente corriente (más de 100 casos en la litoratura), pero la del útero crávido normal está rete. rida sólo 33 veces, sin contar nuestro CCABO.

Para que ocurra la torsión axial del - Ĺtero grávido normal es preciso que el órgano se asemoje mucho $c$ un tumor pediculado, existiendo' al mismo tiempo un exceso de tracción sobre sus dispositivos de fijación naturales o una función deficiente de los mismos. Lo primero sucede cuando el segmento inferior se encuentra vacío (situación transversal, anomalías pélvicas o del raquis, placenta previa o hidramnios), formando entonces el segmento inferior. Como una especie de pedículo respecto al cuerpo uterino grávido. El exceso de tracción incluye los mo. vimientos bruscos de rotación del cuerpo, los traumas, ventrofijaciones, adherencias, cambios bruscos de postura y otros menos importantes. Pue de cttarse aquí también la versión externa.

La deficiencia funcional de los dispositivos de fijación naturales debe poseer gran importancia. La inhibiclón tisular gravídica, las operaciones de fijación ligamentosa y la existencla de ptosis con astenia facilitaran mucho la torsión. Esto sucede con más trecuencia hacia la derecha que hacia la izquierda. El punto de rotación se encuentra en la unión córvicovaginal, en la unión cérvico-uterina o en la parte media del cérvix.

Se describen tres formas clínicas: la latente, la progresiva o gradual y la brusca, aguda, finalmente. El diagnóstico es extraordinariamente dificil, pues todas las entermas menos dos, fueron diagnosticadias en la mosa de operaciones o on ia de cutopalas. Do lores, síntomas de shock y de anemic aguda, detención del parto, cuello alto $\mathrm{y}$ sin progreso de la dilatación. desprendimiento prematuro de pla. centa normalmente insertada $\mathrm{y}$ e ligamento redondo cruzando oblicuemente ol abdomen, son sintomas que se presentan en estos casos. 
E! pronostico fetal es desfavorable en las formas bruscas y también en los graduales si no se opera en el momento oportuno. El tratamiento es la cesarea, seguida o no de histerectomía, si existen motivos pära ello.

\section{Clínica obstétrica de la onlormedad hemolítica del foto.}

Manuel Luis Pérez-Obato. I Clas. Latinoam. Vol. $X$ enero $y$ febrero 1952.

El mundialmente conocido obsto tra argentino se refiere a los métodos de Kariher (disulfonato de etileno), de Carter (haptenos) y de Wiener (antigenos mas potentes quie el $R$ h), para decir que en la actualidad aún 'no se cuenta con una verdadera terapéutica profiláctica de la eritroblastosis. El pronóstico exige la determinación del genotipo del padre, ya que si es homocigote al factor Rh todos los to tos por él engendrados on una mujer Rh negativa serán positivos, y si es heterocigote los fetos pueden ser positivos o negativos en la misma proporción.

En la Maternidad a cargo del Profesor Perez se siguen las siquientes difectivas terapéuticas:

at Se poralte la llegaciu de la pro ñez a su térmíno y el parto espontáneo cuand faltan antecedentes obstétri- ves de enfermedad hemolítica, el padre es heterocigote $y$ las investigaciones serológicas escalonadas han probado una isosensibilización tardía sin mayor tendencia a acrecentarse.

b) También-se permite :a llegada al término cuando se trata de la forma hidrópica generalizada, pues todo-intento de salvación es inútil.

c) Cuando son muchas las probabilidades de que el feto padezca de enfermedad hemolítica, se interrumpe prematuramente el embarazo para que la curación del mal que el feto trae a la vida sea más factible, pues 60 pre sume que sus lesiones no bon aún irreversibles y que así se sustrae al feto de la agresión de anticuerpos: la cesárea lo defiende más del paso de aglutininas.

d) Si se sospecha que la agresión al feto es poca, se prefiere la inducción médica; por el contrario, si hay graves antecedentes y progresiva ttulación de anticuerpos, el método más aconsejable es la cesćrea.

-) Extraido ol feto practica una transfusión simple o una ex-sanquino. transfusión.

f) Se reserva el aborto para aquellos casos en que las gestaciones, - dentro de las seguridades dadas por el estudio de los factores en juego. nunca se ven satisfechas con el naclmiento de un feto vivo o susceptible de eurars. (i) thecorcamos que la thitein Calólica nunca permite el Hamado aborto terapéuttco). 